\title{
COMPARATIVE STUDY BETWEEN INTRATHECAL BUPIVACAINE WITH DEXMEDETOMIDINE AND INTRATHECAL BUPIVACAINE WITH FENTANYL FOR LOWER ABDOMINAL SURGERIES. A RANDOMIZED DOUBLE BLINDED CONTROLLED CLINICAL TRIAL
}

\author{
Leelavathy P. B1, Salim Iqbal², Ahmedi Fathima ${ }^{3}$
}

${ }^{1}$ Associate Professor, Department of Anaesthesiology, Dr. B. R. Ambedkar Medical College \& Hospital, Bangalore. ${ }^{2}$ Associate Professor, Department of Anaesthesiology, Dr. B. R. Ambedkar Medical College \& Hospital, Bangalore. ${ }_{3}^{3}$ Assistant Professor, Department of Anaesthesiology, Dr. B. R. Ambedkar Medical College \& Hospital, Bangalore.

\begin{tabular}{l}
\hline ABSTRACT \\
\hline BACKGROUND \\
Spinal anaesthesia is preferred choice of anaesthesia in lower abdominal surgeries since long time. Various adjuvants have been \\
used with local anaesthetics in spinal anaesthesia to provide prolonged postoperative analgesia. Dexmedetomidine, the new highly \\
selective $\alpha 2$-agonist drug, is now being used as a neuraxial adjuvant. This prospective, randomized, double blinded study was \\
conducted to evaluate the onset, duration of sensory and motor blockade, haemodynamic stability and adverse effects of \\
dexmedetomidine and fentanyl when given intrathecally with $0.5 \%$ hyperbaric bupivacaine.
\end{tabular}

\section{MATERIALS AND METHODS}

A total of 60 patients of ASA I and II scheduled for elective lower abdominal surgeries were selected and randomly allocated into 2 groups of 30 each. Group D received $0.5 \%$ hyperbaric bupivacaine (15 mg) plus dexmedetomidine ( $10 \mu \mathrm{g})$, Group F received $0.5 \%$ hyperbaric bupivacaine $(15 \mathrm{mg}$ ) plus $25 \mu \mathrm{g}$ fentanyl intrathecally. The onset of sensory and motor blockade, duration of sensory and motor blockade, duration of analgesia, haemodynamic changes and side effects (Nausea, vomiting, pruritus, respiratory depression, bradycardia or hypotension) were recorded.

\section{RESULTS}

Onset of sensory blockade was faster in fentanyl group than dexmedetomidine group, but this was statistically insignificant. Patients in dexmedetomidine group (D) had faster motor onset $(\mathrm{p}<0.01)$ and significantly longer sensory and motor blockade time than patients in fentanyl group $(\mathrm{F})(\mathrm{p}<0.01)$. Duration of analgesia was better with dexmedetomidine $(\mathrm{p}<0.01)$. There were no significant haemodynamic changes or adverse effects in any of the groups. It was observed that sedation was better in Group D.

\section{CONCLUSIONS}

Intrathecal Dexmedetomidine is a better adjuvant than intrathecal Fentanyl with prolonged sensory and motor blockade and profound postoperative analgesia.

\section{KEYWORDS}

0.5\% Hyperbaric Bupivacaine, Dexmedetomidine, Fentanyl.

HOW TO CITE THIS ARTICLE: Leelavathy PB, Iqbal S, Fathima A. Comparative study between intrathecal bupivacaine with dexmedetomidine and intrathecal bupivacaine with fentanyl for lower abdominal surgeries. A randomized double blinded controlled clinical trial. J. Evolution Med. Dent. Sci. 2016;5(41):2543-2546, DOI: 10.14260/jemds/2016/594

\section{INTRODUCTION}

Spinal anaesthesia is the most commonly used technique for lower abdominal surgeries, as it is very economical and easy to administer. Intrathecal use of hyperbaric $0.5 \%$ bupivacaine is appropriate for surgeries of short duration and may lead to early analgesic intervention in the postoperative period. ${ }^{1}$ In search for adjuvants that prolong the duration of analgesia with lesser side effects various drugs as opioids, alpha agonists and midazolam have been tried with local anaesthetics. ${ }^{2}$

The addition of fentanyl to hyperbaric bupivacaine improves the quality of intraoperative and early postoperative subarachnoid block. ${ }^{3}$ The addition of opioids to local anaesthetic solution have disadvantages, such as pruritus and respiratory depression. Dexmedetomidine, a highly selective

Financial or Other, Competing Interest: None.

Submission 03-04-2016, Peer Review 02-05-2016,

Acceptance 07-05-2016, Published 23-05-2016.

Corresponding Author:

Dr. Leelavathy $P . B$,

No. 46/1, $7^{\text {th }}$ Cross, Bhovipalya,

Mahalakshmipuram, Bangalore-86.

E-mail:drleelashekar@gmail.com

DOI: $10.14260 /$ jemds/2016/594 $\alpha 2$-agonist, is under evaluation as a neuraxial adjuvant as it provides stable haemodynamic conditions, good quality of intraoperative and prolonged postoperative analgesia with minimal side effects. ${ }^{4-6}$

In the present study, an attempt has been made to evaluate the efficacy of intrathecal dexmedetomidine with bupivacaine in lower abdominal surgeries when compared to bupivacaine with fentanyl in terms of onset, duration of sensory and motor blockade, duration of analgesia and haemodynamic stability.

\section{MATERIALS AND METHODS}

This prospective, randomized, double blinded, controlled study was conducted at Dr. B. R. Ambedkar Medical College and Hospital, Bangalore, after approval of Ethical Committee of the Institution. Written informed consent was obtained from all patients. Inclusion criteria were ASA grade I and II patients aged 18 to 50 years old undergoing elective lower abdominal surgeries. Exclusion criteria were patient refusal, ASA grade III and IV, coagulopathy, local infections, allergy to bupivacaine, fentanyl or dexmedetomidine.

- A total of 60 patients were selected and randomly allocated into two groups of 30 each. 
- Group D received 0.5\% hyperbaric bupivacaine (15 mg) plus $0.5 \mathrm{~mL}$ dexmedetomidine $(10 \mu \mathrm{g})$.

- Group F received 0.5\% hyperbaric bupivacaine (15 mg) plus $0.5 \mathrm{~mL}(25 \mu \mathrm{g})$ fentanyl intrathecally.

- $\quad$ Pre-anaesthetic evaluation was done. Patients were kept nil by mouth for $8 \mathrm{hrs}$.

- Demographic data of all the patients was noted.

In the operation theatre, appropriate equipment for airway management and emergency drugs were kept ready. The patients were wheeled into the operation theatre and connected to all non-invasive monitors. Baseline parameters including pulse rate, blood pressure and oxygen saturation were noted; 18G IV cannula was secured and patients were preloaded with $10 \mathrm{~mL} / \mathrm{kg}$ Ringer's lactate.

Under strict aseptic precaution, 25-gauge spinal needle was inserted in L3-L4 interspinal space with patient in sitting position using a midline approach. After confirmation with free flow of cerebrospinal fluid, drug was injected. Neither the patient nor the attending anaesthesiologist was aware of the group the patient belonged to.

The time for intrathecal injection was considered as 0 and the following parameters were observed-sensory blockade, motor blockade and duration of analgesia. Adverse effects such as nausea, vomiting, pruritus, respiratory depression, shivering, hypotension and bradycardia were also documented and managed. The pulse rate, systolic and diastolic blood pressure, $\mathrm{SpO} 2$ and respiratory rate were recorded for every $2 \mathrm{~min}$ for $10 \mathrm{~min}$ and then every $5 \mathrm{~min}$ throughout the intraoperative period and at the completion of surgery.

Hypotension was defined as fall in systolic blood pressure $>20 \%$ from baseline or mean arterial pressure $<60$ $\mathrm{mmHg}$ and was managed with injection mephentermine $6 \mathrm{mg}$ intravenous in increments. Bradycardia was defined as heart rate $<50 / \mathrm{min}$ and this was managed with atropine $0.01 \mathrm{mg} / \mathrm{kg}$ intravenously. Respiratory depression defined as respiratory rate $<8 / \mathrm{min}$ and/or $\mathrm{SpO} 2<85 \%$. This was planned to be managed with bag and mask ventilation or intubation if necessary.

Following a subarachnoid block, the sensory block was assessed by loss of sensation to pinprick using 23G sterile needle starting immediately after injection and was continued for every $15 \mathrm{~s}$ till loss of pinprick sensation at T10 level. Onset of sensory block was taken as the time from intrathecal injection to loss of pinprick sensation at T10. Motor block was assessed using Bromage score (1-Free movements of legs and feet, 2-Just able to flex knees with free movement of feet, 3Unable to flex knees but with free movement of feet, 4-Unable to move hips, legs or feet). Assessment of motor block was started immediately after the intrathecal injection. It was tested for every $15 \mathrm{~s}$ till Bromage score of 4 was reached. Onset of motor block was taken as the time taken to achieve Bromage score of 4 from the subarachnoid block. Thereafter, motor block regression was noted and duration of motor block was taken as the time from initiation of SAB to return to Bromage score of 1 . Blood loss was replaced as necessary.

The patient was shifted to a recovery room after completion of surgery. The vital signs were recorded for every $15 \mathrm{~min}$ in the $1^{\text {st }}$ hour after surgery and $30 \mathrm{~min}$ interval for next $2 \mathrm{hrs}$. and thereafter at hourly intervals for next 3 hours. Sensory and motor block assessment was done for every 15 mins till recovery of pinprick sensation to L1 and Bromage score of 1 , respectively. Patients were shifted to the postoperative ward after complete resolution of motor blockade. At the end of the surgery, the degree of pain was assessed using visual analog scale. In the recovery room, pain assessment was done for every 15 mins till score $>4$ was reached. Whenever the patient complained of pain, the rescue analgesic intramuscular diclofenac $75 \mathrm{mg}$ was given. Duration of effective analgesia was defined as time interval between onset of the subarachnoid block and the time when patient first complained of pain. Patients were monitored for $24 \mathrm{hrs}$. to detect the occurrence of side effects. Patients were also enquired about the occurrence of transient neurological symptoms, which was described as pain/paraesthesia in the neck, buttocks, legs or pain radiating to lower extremities after initial recovery from anaesthesia within $72 \mathrm{hrs}$.

\section{STATISTICAL ANALYSIS}

All recorded data were entered using MS-Excel software and analysed using SPSS 20 version software for determining the statistical significance. Results were expressed as mean \pm standard deviation. Proportions were compared using Chi-square test. The "student ' $\mathrm{t}$ ' test" was used to determine whether there was a statistical difference between the study groups. "P" value of $>0.05$ was considered not to be statistically significant, $<0.05$ was considered to be statistically significant, a value of $<0.01$ was highly statistically significant and a " $\mathrm{P}$ " value of $<0.001$ was considered as extremely statistically significant.

\section{OBSERVATION AND RESULTS}

The groups were comparable with respect to their age, sex and weight, because there was no statistical significant difference among the groups ( $\mathrm{p}>0.05)$ as shown in Table 1.

\begin{tabular}{|c|c|c|c|c|}
\hline & & $\begin{array}{l}\text { Group F } \\
\text { (Fentanyl } \\
\text { Group) }\end{array}$ & \begin{tabular}{|c|} 
Group D \\
(Dexmedetomidine \\
Group)
\end{tabular} & P Value \\
\hline Age & & $33.7 \pm 13.57$ & $31.5 \pm 13.76$ & 0.53 \\
\hline \multirow[t]{2}{*}{ Sex } & Males & 24 & 25 & \multirow[t]{2}{*}{0.73} \\
\hline & Females & 6 & 5 & \\
\hline Weight & & $65.9 \pm 8.1$ & $64 \pm 7.16$ & 0.33 \\
\hline \multicolumn{5}{|c|}{$\begin{array}{c}\text { Table 1: Comparison of Demographic } \\
\text { Data in Both the Groups }\end{array}$} \\
\hline
\end{tabular}

The sensory onset time in fentanyl group $(1.04 \pm 0.5)$ was shorter than dexmedetomidine group $(1.17 \pm 0.54)$, but this was statistically not significant $(\mathrm{p}=0.33)$. The onset time of motor blockade was shorter in dexmedetomidine group $(1.32 \pm 0.34)$ compared to fentanyl group $(2.05 \pm 0.4)$ and this was highly statistically significant $(\mathrm{p}<0.01)$.

The duration of sensory and motor blockade was more in dexmedetomidine group $(406.66 \pm 30.16,364 \pm 38.54)$ compared to fentanyl group $(326.43 \pm 42.23,276 \pm 34.51)$, which was statistically significant $(\mathrm{p}<0.01)$. The duration of analgesia was better in dexmedetomidine group $(354 \pm 28.1)$ than fentanyl group $(286.6 \pm 32.14)$ and this was statistically significant $(\mathrm{p}<0.01)$. 


\begin{tabular}{|c|c|c|c|c|}
\hline Characteristics & $\begin{array}{c}\text { Group F } \\
\text { (Fentanyl } \\
\text { Group) } \\
\text { Mean } \pm \text { SD }\end{array}$ & $\begin{array}{c}\text { Group D } \\
\text { (Dexmedetomidine } \\
\text { Group) } \\
\text { Mean } \pm \text { SD }\end{array}$ & $\begin{array}{c}\text { T } \\
\text { Value }\end{array}$ & $\begin{array}{c}\text { P } \\
\text { Value }\end{array}$ \\
\hline $\begin{array}{c}\text { Onset of sensory } \\
\text { block (Mins) }\end{array}$ & $1.04 \pm 0.5$ & $1.17+0.54$ & 0.967 & 0.337 \\
\hline $\begin{array}{c}\text { Onset of motor } \\
\text { block (Sec) }\end{array}$ & $2.05 \pm 0.4$ & $1.32+0.34$ & 7.61 & 0.001 \\
\hline $\begin{array}{c}\text { Duration of } \\
\text { analgesia }\end{array}$ & $286.67 \pm 32.14$ & $354 \pm 28.12$ & 8.63 & 0.001 \\
\hline $\begin{array}{c}\text { Duration of } \\
\text { sensory block } \\
\text { (Mins) }\end{array}$ & $326.43 \pm 42.23$ & $406.66 \pm 30.16$ & 8.46 & 0.001 \\
\hline $\begin{array}{c}\text { Duration of } \\
\text { motor block } \\
\text { (Mins) }\end{array}$ & $276 \pm 34.51$ & $364 \pm 38.54$ & 9.31 & 0.001 \\
\hline
\end{tabular}

Incidence of hypotension and bradycardia was higher in dexmedetomidine group, but this was statistically insignificant. However, significant bradycardia was observed only in 3 cases; it was transient and responded well to awakening the patient. Hypotension was seen in 5 patients in group $D$ and 3 patients in group $F$, which was easily managed with bolus IV fluids and inj. Mephentermine bolus. In group F, 2 patients had pruritus and 2 patients had nausea and vomiting.

\begin{tabular}{|c|c|c|}
\hline Complications & Group F & Group D \\
\hline Hypotension (MAP <60 mmHg) & 03 & 05 \\
\hline Bradycardia (HR <60/min) & 00 & 02 \\
\hline Pruritus & 02 & 00 \\
\hline Nausea and Vomiting & 02 & 00 \\
\hline \multicolumn{2}{|c|}{ Table 3: Complications } \\
\hline
\end{tabular}

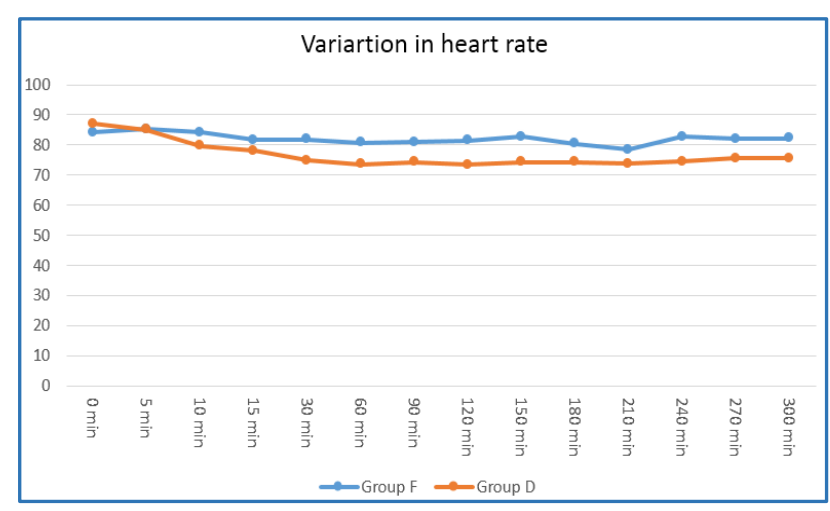

Chart 1: Variation in Heart Rate

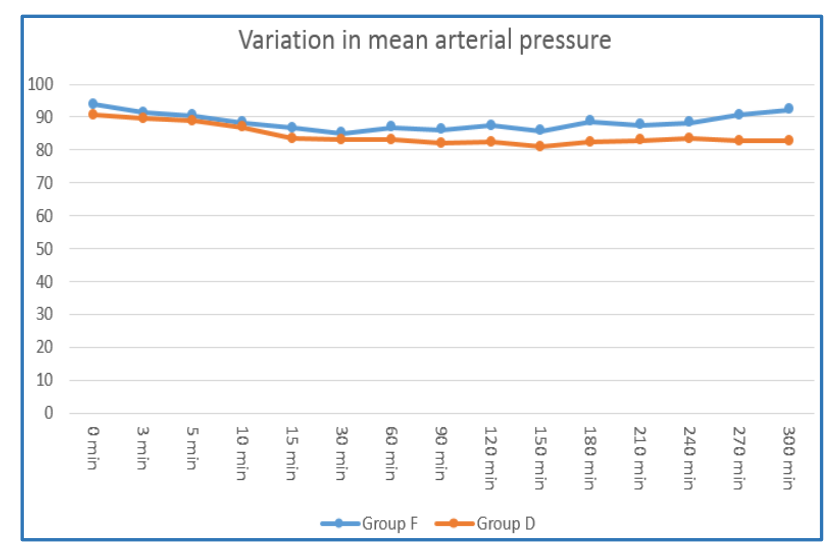

Chart 2: Variation in Mean Arterial Pressure

\section{DISCUSSION}

Following the successful use of intrathecal dexmedetomidine in animal studies in a dose range of 2.5-100 $\mu$ g. ${ }^{7-10}$, its use in human studies has also shown promising results in terms of early sensory and motor blocks and enhanced postoperative analgesic effect.11-14 On the other hand fentanyl, a lipophilic $\mu$ receptor agonist opioid, is being used as an adjuvant for a long time with no major complications. 15

Intrathecal dexmedetomidine acts by binding to the presynaptic C-fibers and postsynaptic dorsal horn neurons. They produce analgesia by depressing release of C-fiber transmitters and by hyperpolarization of post synaptic dorsal horn neurons. $4,6,16$ The prolongation of the motor block of spinal anaesthetics may result from the binding of $\alpha 2$ adrenoceptor agonists to motor neurons in the dorsal horn. ${ }^{17}$

In our study, we made an attempt to study the efficacy of dexmedetomidine and fentanyl as an adjuvant to intrathecal Bupivacaine.

Aamir et al18 did a comparative study between intrathecal dexmedetomidine and fentanyl as adjuvant to intrathecal bupivacaine in lower abdominal surgeries and they found out that highest sensitivity level of T6 and T8 was achieved by higher proportion of subjects from dexmedetomidine Group when compared to Fentanyl Group. Duration of analgesic properties was significantly higher in dexmedetomidine Group.

Vidhi et al ${ }^{19}$ compared intrathecal dexmedetomidine, clonidine and fentanyl as adjuvants to hyperbaric bupivacaine for lower limb surgery. The results of their study showed that supplementation of spinal bupivacaine with $5 \mu \mathrm{g}$ dexmedetomidine significantly prolonged both sensory and motor block compared with intrathecal $25 \mu \mathrm{g}$ fentanyl and 30 $\mu$ g clonidine. Quality of analgesia significantly improved with use of dexmedetomidine as an adjuvant when compared to groups containing fentanyl and clonidine or lone bupivacaine.

Rajni Gupta et al $^{20}$ did a comparative study of intrathecal dexmedetomidine and fentanyl as adjuvants to Bupivacaine and they found that patients in dexmedetomidine group (D) had a significantly longer sensory and motor block time than patients in fentanyl group (F). The mean time of sensory regression to $\mathrm{S} 1$ was $476 \pm 23 \mathrm{~min}$ in group $\mathrm{D}$ and $187 \pm 12$ min in group $\mathrm{F}(\mathrm{P}<0.001)$. The regression time of motor block to reach modified Bromage 0 was $421 \pm 21 \mathrm{~min}$ in group D and $149 \pm 18$ min in group $\mathrm{F}(\mathrm{P}<0.001)$.

Rabie Soliman et $\mathrm{al}^{21}$ did a comparative study of dexmedetomidine and fentanyl as an adjuvant to epidural Bupivacaine for postoperative pain relief in adult patients undergoing total knee replacement. They showed that the quality of analgesia was better with dexmedetomidine than fentanyl group $(\mathrm{p}<0.05)$, and the requirement for opioids was significantly lower with dexmedetomidine than fentanyl group $(\mathrm{p}<0.05)$. The incidence of motor block, bradycardia, hypotension and dry mouth was significantly higher with dexmedetomidine than fentanyl group $(\mathrm{p}<0.05)$.

Farhad et $\mathrm{al}^{22}$ did a study on Intrathecal Dexmedetomidine and Fentanyl as Adjuvant to Bupivacaine on Duration of Spinal Block in Addicted Patients. They found out that Onset of sensory block in DEX group was significantly lower than those of fentanyl $(\mathrm{P}=0.012)$ and control groups $(\mathrm{P}=0.001)$. Duration of sensory block was significantly longer in DEX group compared to Fentanyl $(\mathrm{P}=0.043)$ and control $(\mathrm{P}=0.016)$ groups. Duration of motor block in the DEX group was significantly longer than those of the fentanyl $(\mathrm{P}=0.014)$ 
and control groups. Heart rate and mean arterial pressure were significantly higher in the DEX group at 30,60, 90, 120, and 180 minutes compared to those of the other two groups $(\mathrm{P}<0.05)$.

In our study, the mean time to onset of the sensory block was faster in Group F when compared to Group D, but this was not statistically significant. Onset of motor blockade in Group D was faster than in Group F and this was statistically significant.

The duration of sensory and motor blockade was longer in Group D than in Group F and this was statistically significant.

There is a significant difference between groups in total duration of analgesia with Group D having a much longer duration compared to Group F $(\mathrm{P}<0.001)$.

Incidence of hypotension and bradycardia was higher in dexmedetomidine group, but this was not statistically significant. Side effects like pruritus, nausea and vomiting were observed in fentanyl group.

It was observed that sedation was better with dexmedetomidine.

Complete recovery of sensory and motor function was observed in all the studied patients; 2 weeks after the surgery at the post-operative follow-up visit, patients did not show any neurological deficit.

\section{CONCLUSION}

From our study, we conclude that dexmedetomidine as an adjuvant to intrathecal bupivacaine is superior to fentanyl in terms of profound anaesthesia and postoperative analgesia.

\section{REFERENCES}

1. David LB. Spinal, epidural and caudal anaesthesia. In: Miller RD, ed. Miller's anaesthesia. Philadelphia: Churchill Livingstone $6^{\text {th }}$ edn, 2005;2:1653-83.

2. Mikko Pitkänen. Spinal (Subarachnoid) blockade. In: Cousin MJ, Bridenbaugh PO, Carr DB, et al, eds. Neural blockade in clinical anaesthesia and management of pain. Philadelphia: Lippincot Williams and Wilkins 2009; th edn:213-38.

3. Hunt CO, Naulty JS, Bader AM, et al. Perioperative analgesia with subarachnoid fentanyl-bupivacaine for caesarean delivery. Anaesthesiology 1989;71(4):535-40.

4. Al-Ghanem SM, Massad IM, Al-Mustafa MM, et al. Effect of adding dexmedetomidine versus fentanyl to intrathecal bupivacaine on spinal block characteristics in gynaecological procedures: a double blind controlled study. Am J Appl Sci 2009;6(5):882-7.

5. Al-Mustafa MM, Abu-Halaweh SA, Aloweidi AS, et al. Effect of dexmedetomidine added to spinal bupivacaine for urological procedure. Saudi Med J 2009;30(3):365-70.

6. Kanazi GE, Aouad MT, Jabbour-Khoury SI, et al. Effect of low-dose dexmedetomidine or clonidine on the characteristics of bupivacaine spinal block. Acta Anaesthesiol Scand 2006;50(2):222-7.

7. Eisenach JC, Shafer SL, Bucklin BA, et al. Pharmacokinetics and pharmacodynamics of intraspinal dexmedetomidine in sheep. Anaesthesiology 1994;80(6):1349-59.

8. Shimode N, Fukuoka T, Tanimoto M, et al. The effects of dexmedetomidine and halothane on fos expression in the spinal dorsal horn using a rat postoperative pain model. Neurosci Lett 2003;343(1):45-8.
9. Kalso EA, Pöyhiä R, Rosenberg PH. Spinal antinociception by dexmedetomidine, a highly selective alpha 2adrenergic agonist. Pharmacol Toxicol 1991;68(2):140-3.

10. Asano T, Dohi S, Ohta S, et al. Antinociception by epidural and systemic alpha (2)-adrenoceptor agonists and their binding affinity in rat spinal cord and brain. Anaesth Analg 2000;90(2):400-7.

11. Mystakidou K, Katsouda E, Parpa E, et al. Oral transmucosal fentanyl citrate for the treatment of break through pain in cancer patients: an overview of its pharmacological and clinical characteristics. Am J Hosp Palliat Care 2005;22(3):228-32.

12. Hanks GW, Nugent M, Higgs CM, et al. Oral transmucosal fentanyl citrate in the management of breakthrough pain in cancer: an open, multicentre, dose-titration and longterm use study. Palliat Med 2004;18(8):698-704.

13. Hammargren WR, Henderson GL. Analysing normetabolites of the fentanyls by gas chromatography/electron capture detection. J Anal Toxicol 1988;12(4):183-91.

14. Jansen PA. The development of new synthetic narcotics. In: Estafanous FG, ed. Opioids in anaesthesia. Boston, Mass: Butterworth Publishers 1984;p 37-44.

15. Ben-David B, Miller G, Gavriel R, et al. Low-dose bupivacaine-fentanyl spinal anaesthesia for caesarean delivery. Reg Anaesth Pain Med 2000;25(3):235-9.

16. Lawhead RG, Blaxall HS, Bylund BD. Alpha-2A is the predominant- 2 adrenergic receptor subtype in human spinal cord. Anaesthesiology 1992;77:983-91.

17. Harada $Y$, Nishioka $K$, Kitahata LM, et al. Visceral antinociceptive effects of spinal clonidine combined with morphine, enkephalin, or U50, 488H. Anaesthesiology 1995;83(2):344-52.

18. Aamir Laique Khan, Raj Bahadur Singh, Rajni K Tripathi, et al. A comparative study between intrathecal dexmedetomidine and fentanyl as adjuvant to intrathecal bupivacaine in lower abdominal surgeries: a randomized trial. Anaesth Essays Res 2015;9(2):139-48.

19. Mahendru V, Tewari A, Katyal S, et al. Comparison of intrathecal dexmedetomidine, clonidine, and fentanyl as adjuvants to hyperbaric bupivacaine for lower limb surgery: a double blind controlled study. J Anaesthesiol Clin Pharmacol 2013;29(4):496-502.

20. Gupta R, Bogra J, Verma R, et al. A comparative study of intrathecal dexmedetomidine and fentanyl as adjuvants to Bupivacaine. J Anaesthesiol Clin Pharmacol 2011;27(3):339-43.

21. Soliman R, Eltaweel M. Comparative study of dexmedetomidine and fentanyl as an adjuvant to epidural bupivacaine for postoperative pain relief in adult patients undergoing total knee replacement: a randomized study. J Anaesthesiol Clin Sci 2016;5(1).

22. Farhad Safari, Reza Aminnejad, Seyed Amir Mohajerani, et al. Intrathecal dexmedetomidine and fentanyl as adjuvant to bupivacaine on duration of spinal block in addicted patients. Anaesthesiology and Pain Medicine 2016;6(1):e26714. 